\title{
Orexin A peptidergic system: Comparative physiology, morphology and population between brains of nomal and Alzheimer's disease mice
}

\author{
Peng Zhao \\ Jiangnan University \\ Yaqian You \\ Jiangnan University \\ Zhe Wang \\ Jiangnan University \\ Yanjun Zhou \\ Jiangnan University \\ Gaoshang Chai \\ Jiangnan University \\ Gen Yan \\ Jiangnan University \\ Zhewu Jin \\ Jiangnan University \\ Qing Wang \\ The second Wuxi People's Hospital \\ Hongxu Sun ( $\nabla$ sunhongxu336@jiangnan.edu.cn ) \\ jiangnan university
}

\section{Research Article}

Keywords: Alzheimer's disease, sleep, three-dimensional reconstruction, orexin A neurons, amyloid- $\beta$

Posted Date: June 7th, 2021

DOI: https://doi.org/10.21203/rs.3.rs-220153/v1

License: (c) (1) This work is licensed under a Creative Commons Attribution 4.0 International License.

Read Full License 


\section{Abstract}

Sleep disturbance is common in patients with Alzheimer's disease (AD), and orexin A is a pivotal neurotransmitter for bidirectional regulating the amyloid- $\beta(A \beta)$ deposition of AD brain and poor sleep. In the present study, we examined the characteristic of sleep-wake architecture in APPswe/PSIdE9 (APP/PS1) and A 3 -treated mice using electroencephalogram (EEG) and electromyographic (EMG) analysis. We compared the expression of orexin A, distribution, and morphology of the corresponding orexin A neurons using innovative methods including three-dimensional reconstruction and brain tissue clearing between Wild type (WT) and APP/PS1 mice. Results from our study demonstrated that increased wakefulness and reduced NREM sleep were seen in APP/PS1 and A 3 treated mice while the expression of orexin A was significantly upregulated. Higher density and distribution of orexin A activated neurons were seen in APP/PS1 mice, with a location of $1.06 \mathrm{~mm}$ to $2.30 \mathrm{~mm}$ away from the anterior fontanelle compared to $1.34 \mathrm{~mm}$ to $2.18 \mathrm{~mm}$ away from the anterior fontanelle in WT mice. These results suggested that the population and distribution of orexin A may play an important role in the progression of AD.

\section{Introduction}

Alzheimer's disease (AD) is a progressive and irreversible neurodegenerative disorder characterized by diffused extracellular amyloid plaques deposition and intracellular neurofibrillary tangles (NFT) that results in progressive dementia associated with cognitive impairment, memory loss, and other behavioral abnormalities (Dey et al. 2017; Thal et al. 2019).

Sleep disturbances are commonly seen in patients with AD and affect approximately $25 \%-60 \%$ of patients (Lim et al. 2014). Compared with healthy older adults, individuals with AD suffer from shorter bouts of repid eyes movement (REM) sleep and more slow-wave sleep fragmentation (Vitiello and Prinz 1989; Mander et al. 2016). Insomnia and excessive daytime sleepiness were also common characteristics seen in AD patients (Roth and Brunton 2019; Hamuro et al. 2018).

Animal and human studies have demonstrated that the accumulation of the amyloid- $\beta$ (A $\beta$ ) peptide, a primary cause of amyloid plaques, is a critical event in the pathogenesis of $A D$ as well as poor sleep (Vanderheyden et al. 2018; Brown et al. 2016). Intracerebroventricular administration of $A \beta$ has been identified to serve as a useful AD model which can trigger cognitive impairment, memory defects, and other AD-like alterations in the brain (Zhang et al. 2019b; Facchinetti et al. 2018). Many transgenic flies of $A D$ models overexpressing $A \beta$ peptides have shown significantly disrupted sleep-wake patterns including increased time awake and decreased sleep, including in transgenic APP and presenilin 1 (APP/PS1) mouse (Kent et al. 2018). However, the factors regulating this process are only clearly understood.

The orexinergic nervous system consists of two peptides: the orexin-A/hypocretin-1 and orexin$B /$ hypocretin-2, which are both synthesized by a cluster of neurons in the lateral hypothalamus and perifornical. These two orexins bind to two G-coupled protein receptors i.e. orexin receptors 1 (OX1R, 
HCRTR-1) and 2 (OX2R, HCRTR-2), and participate in regulating the vital body functions, including sleep/wake architecture, food intake, cognition, and memory (Kukkonen et al. 2002; Thal et al. 2019; Burdakov 2019; Li and de Lecea 2020). A previous study demonstrated that orexin is primarily associated with interstitial $A \beta$ level and wakefulness in transgenic AD mice (Kang et al. 2009). Orexin levels of cerebrospinal fluid (CSF) from AD patients were found to be higher than those seen in normal people and they are responsible for regulating wakefulness maintenance and prevent undesirable transitions into sleep (Liguori et al. 2016; Um and Lim 2020). Overexpression of orexins can lead to non-REM sleep fragmentation and REM sleep suppression during daytime (Willie et al. 2011; Makela et al. 2010). Orexin $A$, which has been shown to promote wakefulness, was recently highlighted on $A \beta$ metabolism in animals and humans (Kang et al. 2009; Liguori et al. 2014). However, some studies carried out in humans have displayed conflicting conclusions. The activity of orexin A and its involvement in sleep/wake cycle alterations remain largely unknown, especially, in AD brain. Postmortem analysis revealed that the number of orexin-positive neurons in the hypothalamus and the concentration of orexin in ventricular CSF were reduced in patients with AD when compared with the controls (Fronczek et al. 2012). Some other studies demonstrated higher CSF orexin-A levels in patients with AD when compared to the control group (Dauvilliers et al. 2014; Liguori et al. 2014; Wennstrom et al. 2012). This might be related to sleep deterioration and neurodegeneration (Liguori et al. 2014). Further evidence is needed to understand the link of orexin $A$ to the underlying neurodegenerative process ( $A \beta$ deposition) or secondary to sleep/wake cycle alterations. Determining the morphology, distribution, and neural network for understanding the physiological function of orexin A neuron is essential for developing new clinical treatment strategies for poor sleep and AD. Therefore, the main objective of this study was to investigate sleep-wake features and the expression changes and distribution of orexin $A$ underlying $A D$ models.

\section{Materials And Methods}

\subsection{Animals}

Male double transgenic APP/PS1 (APPswe/PSIdE9) mice with C57BI/6J background aged 8 months were purchased from the Model Animal Center of Nanjing University of China (certificate No. 201501556; license No. SCXK (Su) 2015-001). Age-matched C57BL/6J mice were used as the control Wild type (WT) group. All mice were housed in specific pathogen-free conditions under a 12h:12h light-dark cycle (lights on at $7 \mathrm{AM}$ and lights off at $7 \mathrm{PM}$, illumination intensity $\approx 100 \mathrm{~lx}$ ) at an ambient temperature of $22 \pm 0.5^{\circ} \mathrm{C}$ in the laboratory animal center of Jiangnan University.

The mice used in this study were approved by the Institutional Animal Care and Use Committee at Jiangnan University, Jiangsu, China.

\subsection{Reagent}

Antibodies were purchased from several companies: Anti-c-Fos (Cat. No. sc-166940) from Santa Cruz (Santa Cruz, CA, USA); Anti-orexin A (Cat. No. ab6214) Abcam (Cambridge, MA, USA); Rhodamine Red-Xconjugated goat anti-rabbit/mouse IgG (Cat. No. BA1031; BA1032) from Boster Biological Technology 
(Wuhan, China); $A \beta_{1-42}$ peptide (Cat. No. AS-65178) was purchased from AnaSpec (Bachem, CA, Switzerland); DAPI (Cat. No. C1006) was purchased from Beyotime, China.

\subsection{Experimental Groups and Animal Treatments}

Mice were randomly divided into four major groups ( $\mathrm{n}=20$ for each group): WT (C57BL/6J mice), APP/PS1, NS (WT + saline), and A $\left(W T+A \beta_{1-42}\right)$.

$A \beta_{1-42}$ (Sigma-Aldrich) was prepared as a stock solution at a concentration of $2 \mathrm{mg} / \mathrm{ml}$ in sterile normal saline, and aliquots were stored at $-20^{\circ} \mathrm{C}$. $A \beta_{1-42}$ was aggregated by incubation at $37^{\circ} \mathrm{C}$ for 4 days before use according to the instructions provided by the manufacturer and previous study (Zheng et al. 2013).

Mice were anesthetized with intraperitoneal (i.p.) injection of chloral hydrate (350 mg/kg, i.p). A guide cannula $(\varnothing=0.5 \mathrm{~mm}$, length $=15 \mathrm{~mm}$ ) was stereotaxically implanted into the right lateral ventricle of the mice. The aggregated form of $A \beta_{1-42}(410 \mathrm{pmol} /$ mouse) was administered by intracerebral ventricular, through the planted guide cannula with the flow rate $1 \mu \mathrm{L} / \mathrm{min}$. The coordinates of the guide tip were as follows: anteroposterior $=-0.6 \mathrm{~mm}$; mediolateral $+1.1 \mathrm{~mm}$ and dorsoventral $=-1.0 \mathrm{~mm}$ from bregma; 1 $\mathrm{mm}$ above the lateral ventricle for mice according to the atlases (Zheng et al. 2013). The length of the injection was $1.5 \mathrm{~cm}$.

\subsection{Polygraphic Recordings and Sleep-Wake States Analysis}

For the sleep-wake cycle recording assay, four stainless steel screw cortical electrodes were screwed through the skull into frontal and parietal cortices to record electroencephalogram (EEG). The cortical electrodes were inserted into the dura through two pairs of holes located, respectively, in the frontal (1 $\mathrm{mm}$ lateral and anterior to the bregma) and parietal ( $1 \mathrm{~mm}$ lateral to the lambda) cortices. Three wire electrodes were directly inserted into the neck musculature for EMG recording. The ground electrode was placed on the skull over the cerebellum. Following the surgery, mice were housed in 12 hour dark and 12 hour light for 10 days. All mice were habituated to the recording cages for 3 days before starting the recording. The record was done since 06:00. After saline or $A \beta$ administration for WT mice, mice of each group were placed in a sound-attenuated, ventilated and electrically isolated chamber. EEG and EMG activities were amplified (2000) and filtered (0.5-60 Hz for EEG Model 3500, A-M Systems, WA, USA), and digitalized at a resolution of 256 and $128 \mathrm{~Hz}$ and recorded continuously with CED 1401 MKII (Cambridge Electronic Design Limited (CED), London, UK). The behavior of the mice during light and dark phases in the chamber was monitored and recorded using an infrared video camera. We visually scored polygraphic records by 30-s epochs for wakefulness (W), sleep (NREM), and REM according to previously described criteria validated for mice using a Spike 2 sleep-score script (CED) and with the assistance of spectral analysis by the fast Fourier transform(FFT) (Tsuneki et al. 2010; Harris et al. 2005).

\subsection{RNA isolation, reverse transcription, and quantitative PCR}


After polygraphic recordings and sleep-wake states analysis were done, hypothalamus tissues of mice (10 were chosen from each group randomly) were collected and homogenized. Total RNA was extracted using TRIzol reagent (Corning, Shanghai, China). cDNA was synthesized using ReverTra Ace qPCR RT Kit (Toyobo, Osaka, Japan) and amplified by real-time PCR on a StepOne Plus system (Thermo Fisher Scientific, Waltham, MA, USA) with primer sets for Orexin A (forward, 5'- GCCTCAGACTTCTTGGGTATTT3'; reverse, 5'- AGGGAACCTTTGTAGAAGGAAA -3') andGAPDH (forward, 5'-TGCGACTTCAACAGCAACTC-3'; reverse, 5'-CTTGCTCAGTGTCCTTGCTG-3'). The relative expression (defined as fold change) of the target gene was given by $2^{-\triangle \triangle \mathrm{Ct}}$ and normalized to GAPDH. At least triplicate independent experiments were performed.

\subsection{Immunohistochemistry of sequence sections}

After polygraphic recordings and sleep-wake states analysis were done, 10 mice chosen randomly from each group were anesthetized with sodium pentobarbital (i.p. $80 \mathrm{mg} / \mathrm{kg}$ ) and then sacrificed by intracardiac perfusion with cold phosphate-buffered saline (PBS) followed by $4 \%$ paraformaldehyde. After perfusion, the whole brain was removed, post-fixed in the same fixative for 2 days, cryoprotected in $30 \%$ sucrose at $4^{\circ} \mathrm{C}$ for 2 days. Brains were embedded in optimal cutting temperature compound (OCT) and cut on a freezing microtome (Leica CM1850; Leica Microsystems UK, Milton Keynes, UK) for acquiring coronal sections $(30 \mu \mathrm{m})$ of the entire hypothalamus. All the sequence sections of these brains were processed for immunostaining. Each section was washed in PBS $(3 \times 5$ minutes $)$ and then processed 30 min in TritonX-100 in PBS, blocked with $5 \%$ bovine serum albumin (BSA) and $0.2 \%$ TritonX100 at room temperature for $1 \mathrm{~h}$. The sections were then incubated with mouse anti-orexin A (1:1000) for $48 \mathrm{~h}$ on a shaker. The sections were washed thrice in PBS and were incubated with biotinylated goat antirabbit lgG. The brown chromogen deposition was shown with 3, 3'-diaminobenzidine tetrahydrochloride (DAB).

\subsection{Tissue optical clearing tracing and deep imaging}

500- $\mu \mathrm{m}$-thick coronal blocks of the brain were cut off and cleared using RapiClear 1.49 (SunJin Lab Co.) by immersing them overnight in the clearing reagent at room temperature. Cleared tissues were mounted on a custom-made sample holder.

Brain tissue from each group (10 mice/group) was dissected out and fixed in a 24-well plate with $4 \%$ paraformaldehyde solution on an orbital shaker for $2 \mathrm{~h}$ at room temperature. The samples were then transferred overnight into $2 \%$ PBST (2\% Triton X-100 in PBS solution) for permeabilization. They were kept overnight in $10 \% \mathrm{BSA}$ on an orbital shaker at $4^{\circ} \mathrm{C}$. The samples were then incubated with the primary antibody on an orbital shaker at $4^{\circ} \mathrm{C}$ for 2 days after which they were incubated with secondary antibody at $4^{\circ} \mathrm{C}$ for 1 day. After being washed with PBST, stain nuclear with DAPI, the imaged was acquired using the microscope (BX60, Olympus, Tokyo, Japan) and software of Imaris 9.3.0.

\subsection{Computer-assisted 3D reconstruction analysis}


The distribution of stained cells was examined and reconstructed three-dimensionally. As described previously (George Paxinos et al. The Mouse Brain in Stereotaxic Coordinates), 130 slices including the hypothalamus that were at a distance of -1.34 to $-2.18 \mathrm{~mm}$ from the bregma were reconstructed in each brain of WT mice. Around 150 slices including the hypothalamus which were at a distance of -1.06 to $-2.30 \mathrm{~mm}$ from the bregma were reconstructed in the APP/PS1 mice. Operate a computer-assisted image processing and three dimensional reconstructions using the ImageJ-win64 software, Adobe Photoshop CS4, and Amira 6.3.0.

\subsection{Statistic Analysis}

Data were expressed as mean \pm SEM and analyzed using Prism 7 (GraphPad; San Diego, CA, USA). Student's t-test was performed to compare the continuous variable between two groups com, and the differences among three or more groups were performed using the analysis of variance (ANOVA). $P$ value less than 0.05 was considered to be statistically significant in all the experiments.

\section{Result}

\subsection{The Sleep-Wake Architecture was disturbed in APP/PS1 and Aß-injected mice}

We assessed the sleep state of APP/PS1 mice and A $\beta$ challenged mice to investigate the acute impact of $A \beta$ on the sleep architecture. Compared to the control groups, APP/PS1 mice increased wakefulness by $42.9 \%$ in the 12 -h light phase, $12.1 \%$ in $24 \mathrm{~h}$ total. Similarly, wakefulness was increased by $43.57 \%$ in the 12-h light phase, $17.62 \%$ in the 12 -h dark phase, and $26.12 \%$ in 24 -h total, respectively in A $\beta$ treated mice (Figure 1A).

The increase in wakefulness was concomitant with the reduction in non-rapid eye movements (NREM) sleep, NREM sleep was decreased by $16.9 \%$ during 12 -h dark period and $10.3 \%$ for 24 -h total in APP/PS1 mice. In $A \beta$ treated mice, it was decreased by $18.41 \%$ in the 12 -h light phase, $21.12 \%$ in the 12 -h dark phase, and $19.62 \%$ in $24-h$ total (Figure 1B).

However, no difference was observed in APP/PS1 or A 3 -treated mice in REM during the $12 \mathrm{~h}$ light, $12 \mathrm{~h}$ dark phases, or $24 \mathrm{~h}$ total when compared to the control group respectively (Figure $1 \mathrm{C}$ ).

Compared to the control groups, the increase increased awakening time in the 12-h light phase of APP/PS1 mice was due to the increase of average duration, while the decrease of NREM was due to the decrease of average duration. There was no significant difference in the average duration and number of REM during the $12 \mathrm{~h}$ light and $12 \mathrm{~h}$ dark phases. Similarly, the increase of awakening caused by treatment with $A \beta$ in the 12-h light phase was due to the increase of average duration, while the decrease of NREM was due to the decrease of average duration and the increase of occurrence number. The increase of awakening caused by treatment with $A \beta$ in 12-h dark period was due to the increase of average duration. The decrease of NREM was due to the decrease of occurrence number. The average duration and number of REM in the 12-h light phase were not statistically significant. However, the 
average duration of REM decreased in the 12-h dark phase while there was no significant change in the number of REM (Figure 1D-G).

An hour-by-hour analysis was carried out on the time course from $24 \mathrm{~h}$ recordings. To begin with lightson, time-course changes showed a significant increase in wakefulness, this effect lasted for several hours. Specifically, an increase in wakefulness of APP/PS1 mice at 07:00, 9:00-10:00, 13:00, and 06:00 with a concomitant decrease in NREM at 07:00, 9:00-10:00, 13:00, and 06:00, in REM the decrease appears at 07:00 and 17:00 (Figure $2 A$ and $B$ ). Increase in wakefulness at 07:00, 8:00, 13:00, 17:00, 18:00, 19:00, 01:00 and 06:00, with a concomitant decrease in NREM at 07:00, 13:00, 17:00, 18:00, 19:00, 01:00, and 06:00 and decrease in REM at 8:00h, 09:00, and 13:00, 18:00,02:00, 06:00 was seen in the mice treated with $A \beta$ (Figure $2 C$ and $D$ ).

\subsection{The number of activated orexin A neurons and expression of orexin A were both upregulated in APP/PS1 and Aß-injected mice}

c-Fos gene, an immediate early gene that is transcribed when neurons are activated, has been extensively used as a marker of the activated neuron (Joo et al. 2016). We assessed the activated hypothalamic orexin neurons by using immunofluorescence staining for c-Fos and orexin A. As shown in Fig $3 A$ and $B$, the number of activated orexin A neurons was significantly increased in APP/PS1 and A

when compared with their relative control groups respectively. Next, we examined the expression of orexin $A$ and found that the mRNA levels of preproorexin, which is the common precursor of orexin A, were significantly upregulated in the APP/PS1 as well as the Aß-injected mice (Figure $3 C$ ).

\subsection{The density and distribution orexin A positive neurons were increased in the brain of APP/PS1 mice}

To demonstrate the rostral to caudal distribution of orexin A neurons in the brain of WT and AD mice, sequence coronal sections of different sectors were selected and analyzed using an immunohistochemistry assay. Orexin A positive neurons were distributed in an ellipsoid shape which was located in upper lateral of fornix, lower lateral of mammillothalamic tract, and symmetrically located on both sides of the third ventricle. The density of orexin A positive neurons in the central sector of tuberal hypothalamus was much higher when compared to the anterior and posterior sectors (Figure 4A, $C$, and E). Compared to WT mice, the number of orexin A neurons totally and in $\mathrm{HL}$ and $\mathrm{VMH}$ in the anterior sector was significantly different (Figure $4 \mathrm{~A}$ and B). On the other hand, there was a statistically higher density of orexin A neuron totally and in LH of the central sector (Figure $4 \mathrm{C}$ and D); and slightly decreased density of orexin A positive neurons totally and in $\mathrm{LH}$ as well as $\mathrm{PeF}$ in the posterior sector of tuberal hypothalamus in APP/PS1 mice when compared to the WT mice (Figure 4E and F,). The total density and distribution range of orexin A positive neurons were significantly higher in the brain of APP/PS1 mice compared to that of WT mice.

\subsection{Three-dimensional reconstruction showed increased orexin A neurons in the brain of AD mice}


Three-dimensional reconstruction was conducted based on the immunohistochemistry image of orexin A positive neurons. Orexin A positive neurons were mainly located in the tubercular hypothalamic region and were accompanied with fornix and mammillothalamic tract in both WT and APP/PS1 mice. The distribution and density of orexin A-positive neurons in APP/PS1 mice were higher in APP/PS1 mice when compared with WT mice (Figure 5A and B). These results indicated that orexin A positive neurons were higher in the brain of AD mice when compared with WT mice.

\subsection{Maps accurately showed the distribution of orexin A positive neurons}

It has been identified that orexin A positive neurons were mainly located in the tuberal hypothalamus (Peyron et al. 1998), and we further analyzed the detailed distribution of orexin A positive neurons using the serial slices from the rostral to caudal of WT and APP/PS1 mice. The results demonstrated orexin A positive neurons were seen at a distance of $1.06 \mathrm{~mm}$ from the bregma that in the APP/PS1 and their number was higher once the distance from the bregma was increased. Most orexin A positive neurons were seen in the lateral hypothalamus area (LH). A few were seen in the ventromedial hypothalamic nucleus (VMH) and supraoptic nucleus (SOR) in $1.22 \mathrm{~mm}$ far away from the bregma, while there has no orexin A positive neurons until this location in WT mice (Figure $6 \mathrm{~A}$ ). The range of orexin A positive neurons in APP/PS1 mice was still limited in the area of $\mathrm{LH}, \mathrm{VMH}$, and SOR even the number of orexin $\mathrm{A}$ neurons increased in $13.4 \mathrm{~mm}$ far away from the bregma, where several orexin A neurons were found in LH of the brain of WT mice. Then, the distribution location changed as the distance increased. Till a distance of $2.06 \mathrm{~mm}$ from the bregma, the orexin A neurons in WT mice were mainly found in the parabrain nucleus (PSTH), perifornix nucleus (PEF), and posterior hypothalamic nucleus (PH). Orexin $A$ positive neurons in the APP/PS1 mice displayed a broader range, locating in another region of medial tuberal nucleus (Mtu) except for PSTH, PEF, and PH (Figure 6B). At a distance of $2.30 \mathrm{~mm}$ from the bregma, orexin A positive neurons in the brain of APP/PS1 mice were found only in $L H$, while no orexin $A$ positive neurons were seen in the brain of WT mice at the same distance (Figure 6C). Taken together, the above data suggested that the orexin A positive neurons appeared earlier, but disappeared later from the rostral to caudal of brain in APP/PS1 mice when compared to WT mice.

\subsection{RapiClear cleared the brain of WT and APP/PS1 mice.}

Generally, the serial slice may arise some deformation and damage of tissues, and inaccuracy may occur during the three-dimensional reconstruction. Thus, we adopted the RapiClear technique to further examine the distribution of orexin A positive neurons, which can keep the tissue structure to analyze the three-dimensional and topological morphology of neurons. As shown in Figure 7A, the brain tissue becomes uniformly transparent after immersion in refractive-index-specified solutions.

The tissue structure, cellular architecture, and fluorescence signals were preserved well in RapiClear cleared brain (Figure 7B). It was also shown that the density of orexin A neurons in the brain of APP/PS1 mice were significantly higher compared to WT mice (Figure 7C). We then observed the morphology of orexin A neurons and found the diameter of these neurons was always around 10-25 $\mu \mathrm{m}$ and did not show any significant difference between the brains of WT and APP/PS1 mice (Figure 7D-F). 


\section{Discussion}

Sleep abnormalities have been observed for decades in AD (Weng et al. 2020). In the present study, we examined the sleep-wake cycle and evaluated the relationship between immunoreactivity and expression of orexin $A$ and $A B$ in the tuberal hypothalamus with a special focus on the spatial distribution of labeled neurons of $A D$ models.

Sleep dysfunction is considered a core component of AD. 6 month-old APP/PS1 AD model has previously been shown to exhibit increased wakefulness during the $12 \mathrm{~h}$ light phase (Zhang et al. 2019a; Zhurakovskaya et al. 2019); some Some other studies have reported that 9 month-old APP/PS1 female mice displayed reduced REM and NREM sleep stages across both light and dark phases (Roh et al. 2012); reduced NREM and increased wakefulness during $12 \mathrm{~h}$ light phase also has been observed in PLB1 Triple (Platt et al. 2011). There is mounting evidence that $A \beta$ amyloidosis plays a key role in the bi-directional regulation of $A D$ pathology in the brain and sleep disorder (Boespflug and lliff 2018). In addition, reduced NREM sleep was also reported to be associated with high cerebrospinal fluid A $\beta 42$ levels in cognitively normal elderly subjects (Varga et al. 2016). Sleep-weak episode number and mean duration have not been previously performed though several studies explored sleep disorder using EEG/EMG in transgenic $A D$ mice. Results from our study demonstrated increased wakefulness with ascendant mean duration and decreased sleep in the time of lights-on and light-off translation in APP/PS1 mice using sleep episode and duration analysis. Our study also revealed that $A \beta$-administrated mice demonstrated excessive awakening and less NREM during the light and dark phase, thus providing direct evidence that the accumulation of $A \beta$ is a crucial factor to promote wakefulness in the progression of $A D$.

The sleep-wake cycle is accurately regulated by many brain areas and neural circuits. This includes the brainstem, midbrain, thalamus, hypothalamus, and basal forebrain. Recently, the orexinergic system is receiving extensive attention in $A D$ for its vital function. High levels of orexin in the cerebrospinal fluid with sleep impairment were seen in patients with AD (Gabelle et al. 2017) (Liguori et al. 2014). Some studies have demonstrated that blocking of the orexinergic system might significantly contribute to a reduced level of $A \beta$ and subsequent awakening (Hagan et al. 1999; Lee et al. 2005). Treatment of sleep disorder has been identified to be an effective strategy for improving pathological changes seen in $A D$ patients with poor sleep (Cousins et al. 2019). Our results demonstrated that the amount of activated orexin A neurons labeled with c-Fos were upregulated, accompanied by enhanced expression of preproorexin in APP/PS1 and A $\beta$-treated mice.

Based on these alterations of physiology and biologic level, we established the anatomical display for spatial distribution, cell density, and cellular morphology of orexin A neurons from the three-dimensional structure. The data demonstrated that neurons immunoreactive to orexin A were distributed in an ellipsoid shape centered in the tuberal hypothalamus and located dorsally to the fornix, with fewer neurons in the anterior and posterior sectors. Central sectors of the brain displayed a higher population of orexin A-positive neurons, which were observed with no significant increase or even small decrease in anterior and posterior sectors of the brain when APP/PS1 mice were compared to the WT mice. This 
phenomenon may be formed of extended area orexin A neurons in APP/PS1 mice leading to a relative lower average subpopulation of each slice in the corresponding sectors, with a location of $1.06 \mathrm{~mm}$ to $2.30 \mathrm{~mm}$ away from the anterior fontanelle in APP/PS1 mice compared to $1.34 \mathrm{~mm}$ to $2.18 \mathrm{~mm}$ away from the anterior fontanelle in normal mice. It has been well established that orexin A positive neurons in LH can regulate sleep-wake cycle behavior via several neural circuits. Orexin receptors exist in monoaminergic neurons including noradrenaline (NE) neurons in LC, histamine (HA) neurons in tuberomammillary nucleus (TMN), and 5-hydroxytryptamine (5-HT) neurons in dorsal raphe nucleus (DRN), which enables orexin neurons to project to them and maintain wakefulness [J Neurosci, 2011, 31(17): 6518-6526.]; Secondly, orexin neurons in the LH region also receive projections from sleep-related nuclei. GABAergic neurons in the ventrolateral preoptic nucleus (VLPO) and median preoptic area (mnpo) densely project to orexin neurons in the LH region. Light stimulation of GABAergic neurons in these two nuclei during sleep can effectively inhibit orexin neurons in the LH region, to maintain sleep state [Front Neural Circuits, 2013, 7: 192]. Here in our study the increase and earlier appearance of distribution and orexin A positive neurons may explain the sleep disorder in AD mice. Additionally, in the AD model, a few orexin A neurons exist in the region of the periventricular nucleus $(\mathrm{PE})$, the margin of the third ventricle. These neurons might contribute to the progression of $A D$ via activation of related mediator-regulated signal protein in CSF of the third ventricle.

The structure, distribution, and projection characteristics of orexin A neurons are the basis for various physiological functions, which determine the properties of synaptic bioelectrical signals and the ability to transmit information. It was reported that there is a functional dichotomy for orexin neurons. Those which are located in perifornical and dorsomedial hypothalamic areas (PFA-DMH) regulate arousal, waking, and response to stress while those which are present in the lateral hypothalamus and ventral tegmental area are involved in reward-based learning and memory (Harris and Aston-Jones 2006). Using a dual retrograde tracer strategy, another study proposed that orexin neurons can be classified based on their downstream projections, whereas these classifications do not show a topographic location within the hypothalamus. Orexin neurons projected to the LC and TMN were mainly involved in wakefulness/arousal populations), and those projected to NAc and VTA regulate reward populations (lyer et al. 2018). A few results were seen for the structure and distribution of orexin A neurons shown from three-dimensional morphology, which was just limited in two-dimensional space (Luna et al. 2017; Cheng et al. 2003). In the current study, we compared the expression, population, and morphology by different experiments including tissue optical clearing tracing, deep imaging, and three-dimensional reconstruction, determining increased population and more extensive distribution in the AD model. Orexin neurons in some regions are indistinct and their function in the regulation of sleep and progression of $A D$ needs to be explored further. Additionally, previous studies have shown that orexin A neurons could be both single and bipolar cells with round, oval, and spindle shapes, exhibiting an average cell diameter of about $21 \mu \mathrm{m}$ in the brain of rats (Cheng et al. 2003). We found the shape of orexin was also diversified in mouse brains with a diameter of 10-25 which was slightly smaller than that of rats.

There is increasing which indicates that the orexin system is strongly implicated in sleep disorder and $A D$ pathogenesis (Kang et al. 2009; Liguori et al. 2020), (Kang et al. 2009; Liguori et al. 2020). Future studies 
should investigate the possibility of potential therapeutic strategy by direct pharmacological intervention at the differentially distributed orexin A neurons in patients with $A D$.

\section{Declarations}

\section{Funding.}

This study was financially supported by the National Natural Science Foundation of China 31500968 , Natural Science Foundation of Jiangsu Province BK20160193, and Research Project of Wuxi Commission of Health Z201711.

\section{Conflict of interest statement}

All authors declare that they have no conflict of interest.

\section{Availability of data, material and code.}

The data, material and code that support the findings of this study are available from the corresponding author [HongXu, Sun], upon reasonable request.

\section{Author contributions.}

Peng Zhao designed the experiments; Yaqian You, Zhe Wang, Yanjun Zhou, Gaoshang, Chai, Zhewu Jin performed the experiments and analyzed the data; Qing Wang and Hongxu Sun prepared the manuscript.

\section{References}

Boespflug EL, Iliff JJ (2018) The Emerging Relationship Between Interstitial Fluid-Cerebrospinal Fluid Exchange, Amyloid-beta, and Sleep. Biological psychiatry 83 (4):328-336.

doi:10.1016/j.biopsych.2017.11.031

Brown BM, Rainey-Smith SR, Bucks RS, Weinborn M, Martins RN (2016) Exploring the bi-directional relationship between sleep and beta-amyloid. Current opinion in psychiatry 29 (6):397-401. doi:10.1097/YCO.0000000000000285

Burdakov D (2019) Reactive and predictive homeostasis: Roles of orexin/hypocretin neurons. Neuropharmacology 154:61-67. doi:10.1016/j.neuropharm.2018.10.024

Cheng SB, Kuchiiwa S, Gao HZ, Kuchiiwa T, Nakagawa S (2003) Morphological study of orexin neurons in the hypothalamus of the Long-Evans rat, with special reference to co-expression of orexin and NADPHdiaphorase or nitric oxide synthase activities. Neuroscience research 46 (1):53-62. doi:10.1016/s01680102(03)00026-9 
Cousins JN, Van Rijn E, Ong JL, Chee MWL (2019) A split sleep schedule rescues short-term topographical memory after multiple nights of sleep restriction. Sleep 42 (4). doi:10.1093/sleep/zsz018

Dauvilliers YA, Lehmann S, Jaussent I, Gabelle A (2014) Hypocretin and brain beta-amyloid peptide interactions in cognitive disorders and narcolepsy. Frontiers in aging neuroscience 6:119. doi:10.3389/fnagi.2014.00119

Dey A, Bhattacharya R, Mukherjee A, Pandey DK (2017) Natural products against Alzheimer's disease: Pharmaco-therapeutics and biotechnological interventions. Biotechnology advances 35 (2):178-216. doi:10.1016/j.biotechadv.2016.12.005

Facchinetti R, Bronzuoli MR, Scuderi C (2018) An Animal Model of Alzheimer Disease Based on the Intrahippocampal Injection of Amyloid beta-Peptide (1-42). Methods in molecular biology 1727:343-352. doi:10.1007/978-1-4939-7571-6_25

Fronczek R, van Geest S, Frolich M, Overeem S, Roelandse FW, Lammers GJ, Swaab DF (2012) Hypocretin (orexin) loss in Alzheimer's disease. Neurobiology of aging 33 (8):1642-1650.

doi:10.1016/j.neurobiolaging.2011.03.014

Gabelle A, Jaussent I, Hirtz C, Vialaret J, Navucet S, Grasselli C, Robert P, Lehmann S, Dauvilliers Y (2017) Cerebrospinal fluid levels of orexin-A and histamine, and sleep profile within the Alzheimer process. Neurobiology of aging 53:59-66. doi:10.1016/j.neurobiolaging.2017.01.011

Hagan JJ, Leslie RA, Patel S, Evans ML, Wattam TA, Holmes S, Benham CD, Taylor SG, Routledge C, Hemmati P, Munton RP, Ashmeade TE, Shah AS, Hatcher JP, Hatcher PD, Jones DN, Smith MI, Piper DC, Hunter AJ, Porter RA, Upton N (1999) Orexin A activates locus coeruleus cell firing and increases arousal in the rat. Proceedings of the National Academy of Sciences of the United States of America 96 (19):10911-10916. doi:10.1073/pnas.96.19.10911

Hamuro A, Honda M, Wakaura Y (2018) Suvorexant for the treatment of insomnia in patients with Alzheimer's disease. The Australian and New Zealand journal of psychiatry 52 (2):207-208. doi:10.1177/0004867417747402

Harris GC, Aston-Jones G (2006) Arousal and reward: a dichotomy in orexin function. Trends in neurosciences 29 (10):571-577. doi:10.1016/j.tins.2006.08.002

Harris GC, Wimmer M, Aston-Jones G (2005) A role for lateral hypothalamic orexin neurons in reward seeking. Nature 437 (7058):556-559. doi:10.1038/nature04071

lyer M, Essner RA, Klingenberg B, Carter ME (2018) Identification of discrete, intermingled hypocretin neuronal populations. The Journal of comparative neurology 526 (18):2937-2954.

doi:10.1002/cne. 24490 
Joo JY, Schaukowitch K, Farbiak L, Kilaru G, Kim TK (2016) Stimulus-specific combinatorial functionality of neuronal c-fos enhancers. Nature neuroscience 19 (1):75-83. doi:10.1038/nn.4170

Kang JE, Lim MM, Bateman RJ, Lee JJ, Smyth LP, Cirrito JR, Fujiki N, Nishino S, Holtzman DM (2009) Amyloid-beta dynamics are regulated by orexin and the sleep-wake cycle. Science 326 (5955):1005-1007. doi:10.1126/science.1180962

Kent BA, Strittmatter SM, Nygaard HB (2018) Sleep and EEG Power Spectral Analysis in Three Transgenic Mouse Models of Alzheimer's Disease: APP/PS1, 3xTgAD, and Tg2576. Journal of Alzheimer's disease : JAD 64 (4):1325-1336. doi:10.3233/JAD-180260

Kukkonen JP, Holmqvist T, Ammoun S, Akerman KE (2002) Functions of the orexinergic/hypocretinergic system. American journal of physiology Cell physiology 283 (6):C1567-1591. doi:10.1152/ajpcell.00055.2002

Lee MG, Hassani OK, Jones BE (2005) Discharge of identified orexin/hypocretin neurons across the sleepwaking cycle. The Journal of neuroscience : the official journal of the Society for Neuroscience 25 (28):6716-6720. doi:10.1523/JNEUROSCI.1887-05.2005

Li SB, de Lecea L (2020) The hypocretin (orexin) system: from a neural circuitry perspective. Neuropharmacology 167:107993. doi:10.1016/j.neuropharm.2020.107993

Liguori C, Nuccetelli M, Izzi F, Sancesario G, Romigi A, Martorana A, Amoroso C, Bernardini S, Marciani MG, Mercuri NB, Placidi F (2016) Rapid eye movement sleep disruption and sleep fragmentation are associated with increased orexin-A cerebrospinal-fluid levels in mild cognitive impairment due to Alzheimer's disease. Neurobiology of aging 40:120-126. doi:10.1016/j.neurobiolaging.2016.01.007

Liguori C, Romigi A, Nuccetelli M, Zannino S, Sancesario G, Martorana A, Albanese M, Mercuri NB, Izzi F, Bernardini S, Nitti A, Sancesario GM, Sica F, Marciani MG, Placidi F (2014) Orexinergic system dysregulation, sleep impairment, and cognitive decline in Alzheimer disease. JAMA neurology 71 (12):1498-1505. doi:10.1001/jamaneurol.2014.2510

Liguori C, Spanetta M, Izzi F, Franchini F, Nuccetelli M, Sancesario GM, Di Santo S, Bernardini S, Mercuri NB, Placidi F (2020) Sleep-Wake Cycle in Alzheimer's Disease Is Associated with Tau Pathology and Orexin Dysregulation. Journal of Alzheimer's disease : JAD 74 (2):501-508. doi:10.3233/JAD-191124

Lim MM, Gerstner JR, Holtzman DM (2014) The sleep-wake cycle and Alzheimer's disease: what do we know? Neurodegenerative disease management 4 (5):351-362. doi:10.2217/nmt.14.33

Luna SL, Brown DI, Eghlidi DH, Kohama SG, Urbanski HF (2017) Locomotor activity and the expression of orexin $A$ and orexin $B$ in aged female rhesus macaques. Neurobiology of aging 50:1-4.

doi:10.1016/j.neurobiolaging.2016.10.016 
Makela KA, Wigren HK, Zant JC, Sakurai T, Alhonen L, Kostin A, Porkka-Heiskanen T, Herzig KH (2010) Characterization of sleep-wake patterns in a novel transgenic mouse line overexpressing human preproorexin/hypocretin. Acta physiologica 198 (3):237-249. doi:10.1111/j.1748-1716.2009.02068.x

Mander BA, Winer JR, Jagust WJ, Walker MP (2016) Sleep: A Novel Mechanistic Pathway, Biomarker, and Treatment Target in the Pathology of Alzheimer's Disease? Trends in neurosciences 39 (8):552-566. doi:10.1016/j.tins.2016.05.002

Peyron C, Tighe DK, van den Pol AN, de Lecea L, Heller HC, Sutcliffe JG, Kilduff TS (1998) Neurons containing hypocretin (orexin) project to multiple neuronal systems. The Journal of neuroscience : the official journal of the Society for Neuroscience 18 (23):9996-10015

Platt B, Drever B, Koss D, Stoppelkamp S, Jyoti A, Plano A, Utan A, Merrick G, Ryan D, Melis V, Wan H, Mingarelli M, Porcu E, Scrocchi L, Welch A, Riedel G (2011) Abnormal cognition, sleep, EEG and brain metabolism in a novel knock-in Alzheimer mouse, PLB1. PloS one 6 (11):e27068.

doi:10.1371/journal.pone.0027068

Roh JH, Huang Y, Bero AW, Kasten T, Stewart FR, Bateman RJ, Holtzman DM (2012) Disruption of the sleep-wake cycle and diurnal fluctuation of beta-amyloid in mice with Alzheimer's disease pathology. Science translational medicine 4 (150):150ra122. doi:10.1126/scitranslmed.3004291

Roth T, Brunton S (2019) Identification and Management of Insomnia in Alzheimer's Disease. The Journal of family practice 68 (8):S32-S38

Thal DR, Ronisz A, Tousseyn T, Rijal Upadhaya A, Balakrishnan K, Vandenberghe R, Vandenbulcke M, von Arnim CAF, Otto M, Beach TG, Lilja J, Heurling K, Chakrabarty A, Ismail A, Buckley C, Smith APL, Kumar S, Farrar G, Walter J (2019) Different aspects of Alzheimer's disease-related amyloid beta-peptide pathology and their relationship to amyloid positron emission tomography imaging and dementia. Acta neuropathologica communications 7 (1):178. doi:10.1186/s40478-019-0837-9

Tsuneki H, Wada T, Sasaoka T (2010) Role of orexin in the regulation of glucose homeostasis. Acta physiologica 198 (3):335-348. doi:10.1111/j.1748-1716.2009.02008.x

Um YH, Lim HK (2020) Orexin and Alzheimer's Disease: A New Perspective. Psychiatry investigation. doi:10.30773/pi.2020.0136

Vanderheyden WM, Lim MM, Musiek ES, Gerstner JR (2018) Alzheimer's Disease and Sleep-Wake Disturbances: Amyloid, Astrocytes, and Animal Models. The Journal of neuroscience : the official journal of the Society for Neuroscience 38 (12):2901-2910. doi:10.1523/JNEUROSCI.1135-17.2017

Varga AW, Wohlleber ME, Gimenez S, Romero S, Alonso JF, Ducca EL, Kam K, Lewis C, Tanzi EB, Tweardy S, Kishi A, Parekh A, Fischer E, Gumb T, Alcolea D, Fortea J, Lleo A, Blennow K, Zetterberg H, Mosconi L, Glodzik L, Pirraglia E, Burschtin OE, de Leon MJ, Rapoport DM, Lu SE, Ayappa I, Osorio RS (2016) 
Reduced Slow-Wave Sleep Is Associated with High Cerebrospinal Fluid Abeta42 Levels in Cognitively Normal Elderly. Sleep 39 (11):2041-2048. doi:10.5665/sleep.6240

Vitiello MV, Prinz PN (1989) Alzheimer's disease. Sleep and sleep/wake patterns. Clinics in geriatric medicine 5 (2):289-299

Weng YY, Lei X, Yu J (2020) Sleep spindle abnormalities related to Alzheimer's disease: a systematic minireview. Sleep medicine 75:37-44. doi:10.1016/j.sleep.2020.07.044

Wennstrom M, Londos E, Minthon L, Nielsen HM (2012) Altered CSF orexin and alpha-synuclein levels in dementia patients. Journal of Alzheimer's disease : JAD 29 (1):125-132. doi:10.3233/JAD-2012-111655

Willie JT, Takahira H, Shibahara M, Hara J, Nomiyama M, Yanagisawa M, Sakurai T (2011) Ectopic overexpression of orexin alters sleep/wakefulness states and muscle tone regulation during REM sleep in mice. Journal of molecular neuroscience : MN 43 (2):155-161. doi:10.1007/s12031-010-9437-7

Zhang F, Zhong R, Li S, Fu Z, Wang R, Wang T, Huang Z, Le W (2019a) Alteration in sleep architecture and electroencephalogram as an early sign of Alzheimer's disease preceding the disease pathology and cognitive decline. Alzheimer's \& dementia : the journal of the Alzheimer's Association 15 (4):590-597. doi:10.1016/j.jalz.2018.12.004

Zhang P, Kishimoto Y, Grammatikakis I, Gottimukkala K, Cutler RG, Zhang S, Abdelmohsen K, Bohr VA, Misra Sen J, Gorospe M, Mattson MP (2019b) Senolytic therapy alleviates Abeta-associated oligodendrocyte progenitor cell senescence and cognitive deficits in an Alzheimer's disease model. Nature neuroscience 22 (5):719-728. doi:10.1038/s41593-019-0372-9

Zheng M, Liu J, Ruan Z, Tian S, Ma Y, Zhu J, Li G (2013) Intrahippocampal injection of Abeta1-42 inhibits neurogenesis and down-regulates IFN-gamma and NF-kappaB expression in hippocampus of adult mouse brain. Amyloid : the international journal of experimental and clinical investigation : the official journal of the International Society of Amyloidosis 20 (1):13-20. doi:10.3109/13506129.2012.755122

Zhurakovskaya E, Ishchenko I, Gureviciene I, Aliev R, Grohn O, Tanila H (2019) Impaired hippocampalcortical coupling but preserved local synchrony during sleep in APP/PS1 mice modeling Alzheimer's disease. Scientific reports 9 (1):5380. doi:10.1038/s41598-019-41851-5

\section{Figures}


A

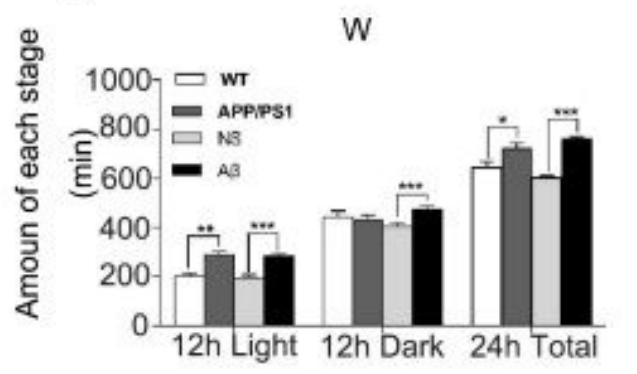

D

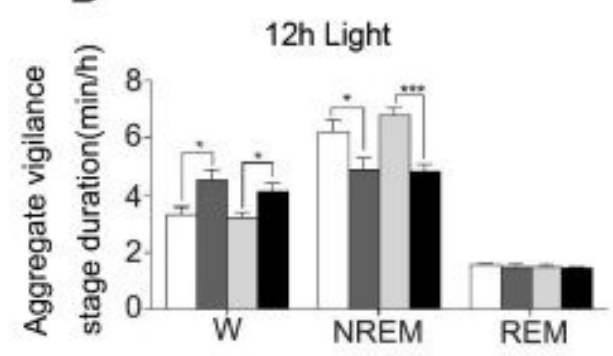

$\mathbf{F}$

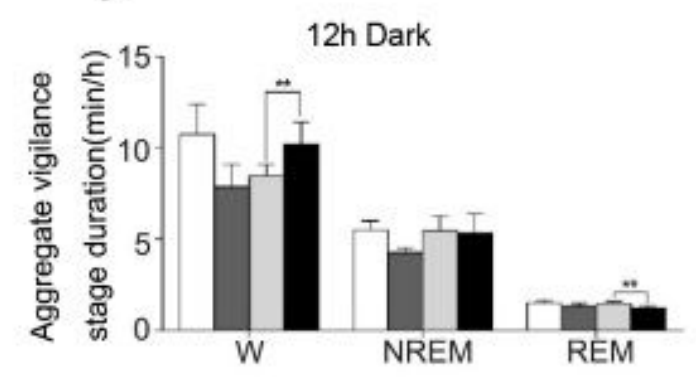

B

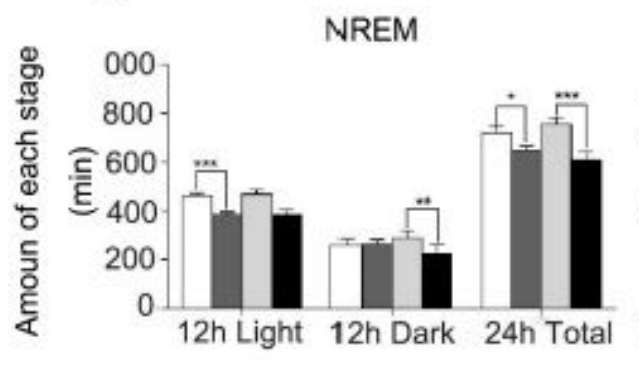

C

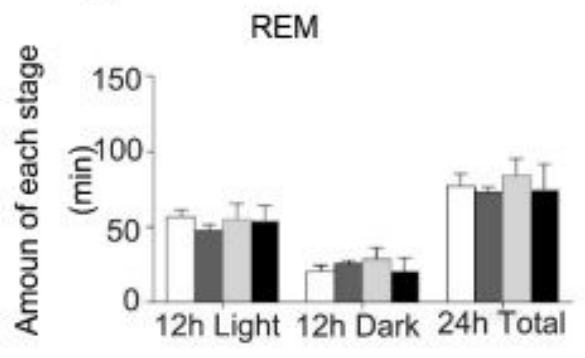

E

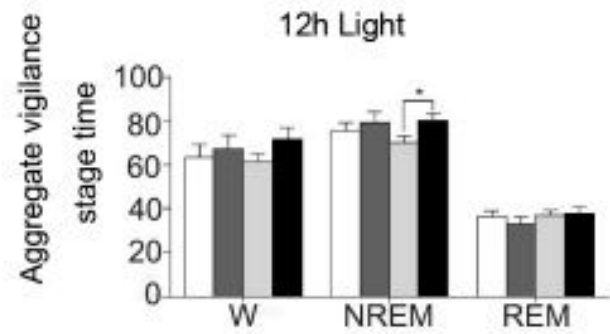

G

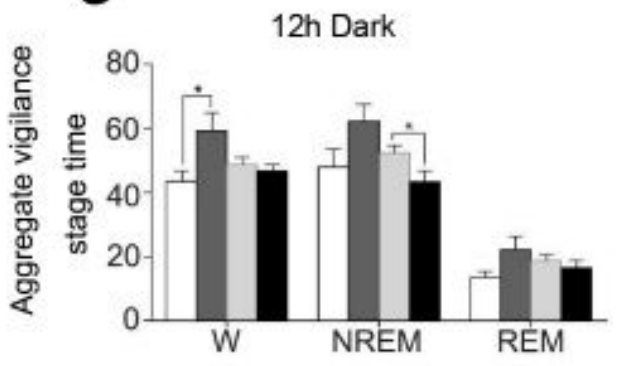

Figure 1

Sleep characteristics of WT, APP/PS1, saline, or A -treated groups. For these four indicated mice groups, ( $\mathrm{A}, \mathrm{B}$, and $\mathrm{C}$ ) Total time spent in W, NREM, and REM during the $12 \mathrm{~h}$ light, $12 \mathrm{~h}$ dark phases, and $24 \mathrm{~h}$ total was calculated; (D, E, F, and G) Time course of the changes in wakefulness, REM sleep, and NREM sleep were calculated. Data expressed as means \pm SEM $(n=6-8) .{ }^{*} \mathrm{P} \otimes 0.05,{ }^{\star} * \mathrm{P} \llbracket 0.01,{ }^{*} * \mathrm{P} \otimes 0.001$. Data were analyzed using Student's t-test. 


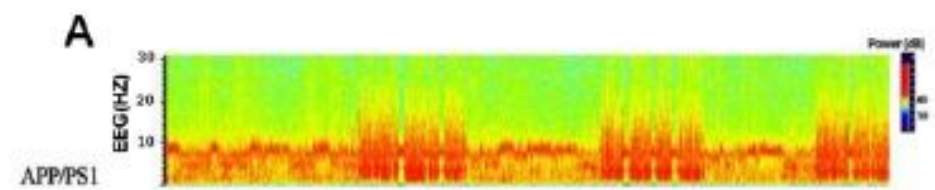

C
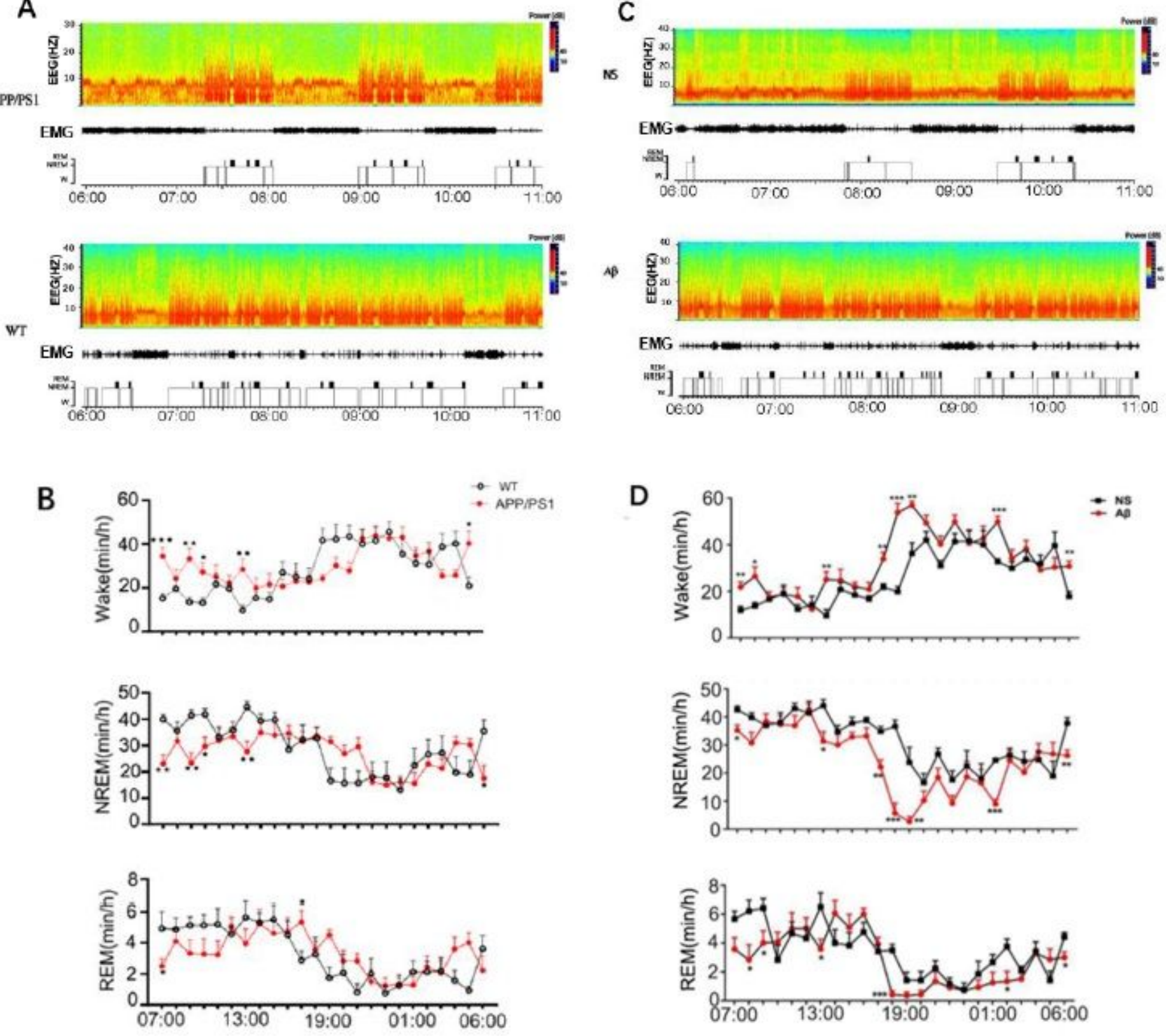

Figure 2

Sleep characteristics of WT, APP/PS1, saline, or A -treated groups. (A, B, C, and D) Representative spectrograms of EMG and brain state from 06:00 to 11:00 are shown. Data expressed as means \pm SEM

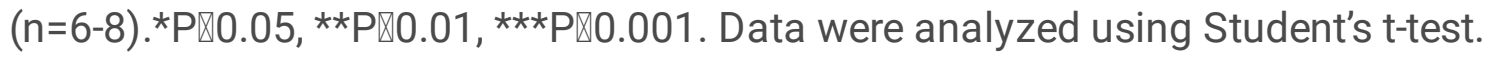



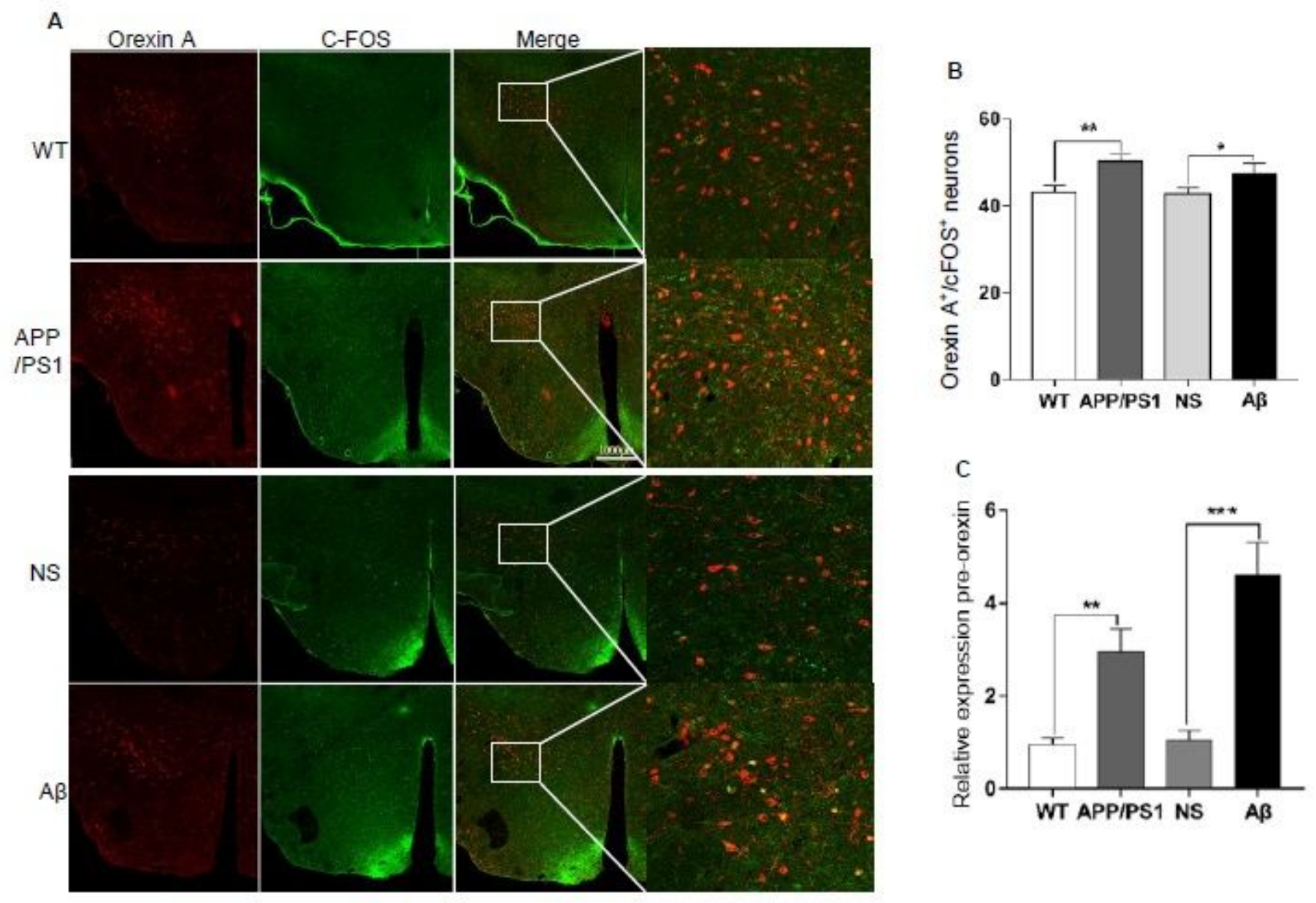

Figure 3

Orexin A neuronal activity and expression of orexin A were ascendant in APP/PS1, and A 3 -treated mice. (A) Immunofluorescence assay of orexin A and c-Fos in the different groups. (B) Quantitative analysis of c-Fos positive orexin A neurons. (C) The prepro-orexin gene expression in the hypothalamus of different

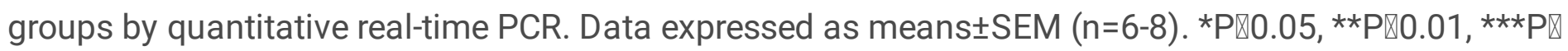
0.001. Data were analyzed using Student's t-test. 
A

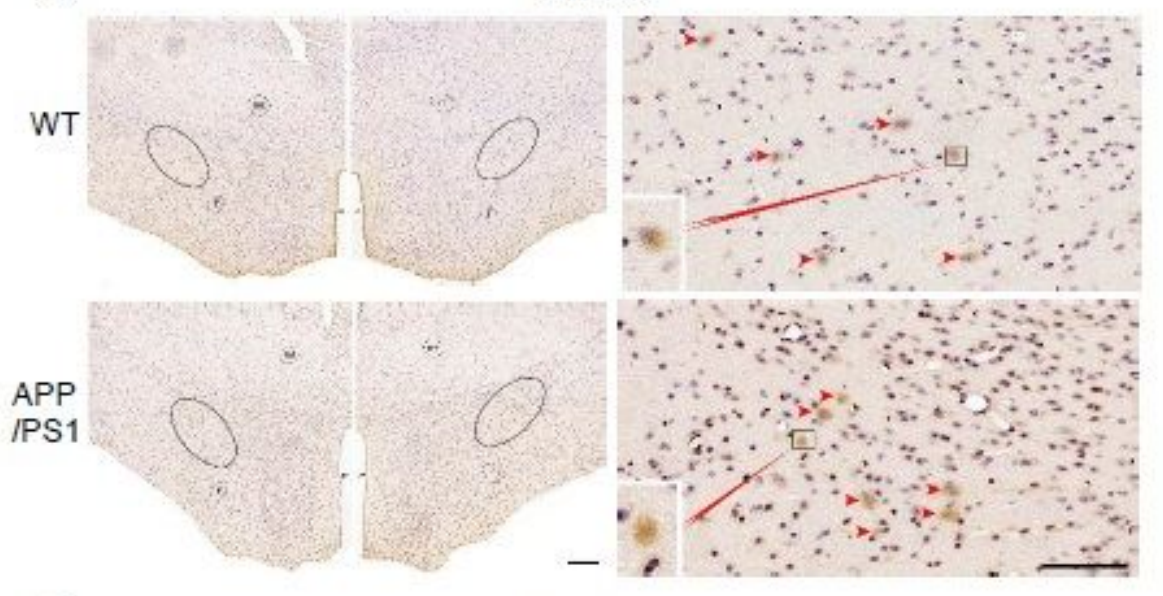

C
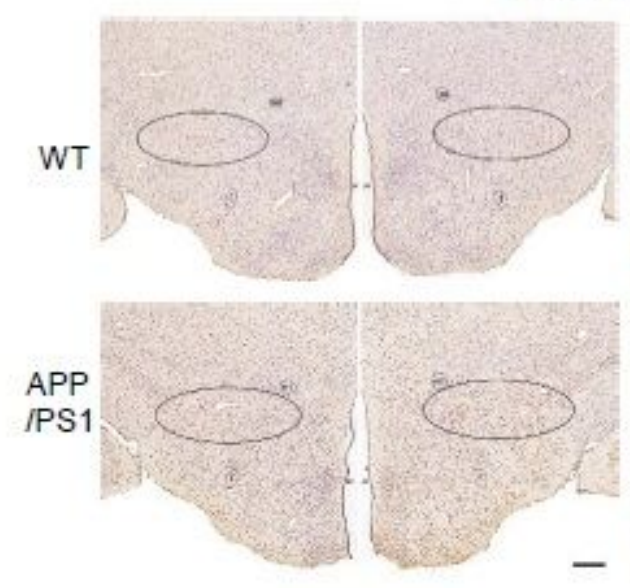

Central

E

Posterior

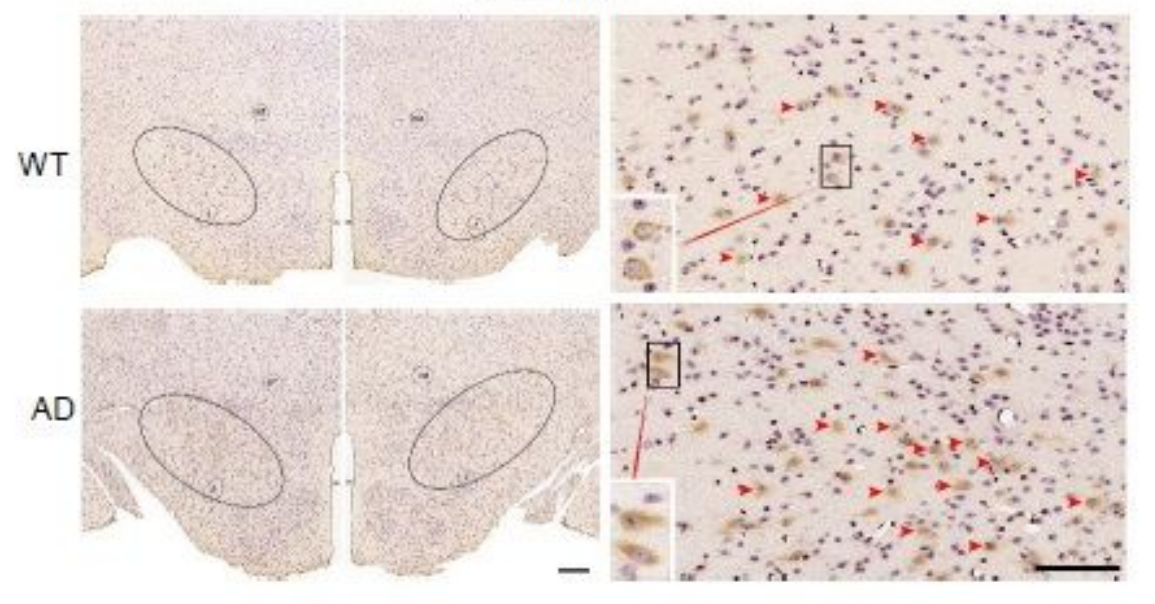

B

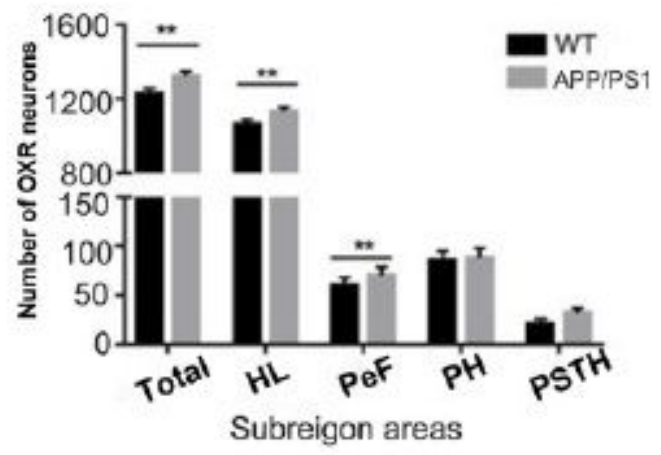

D

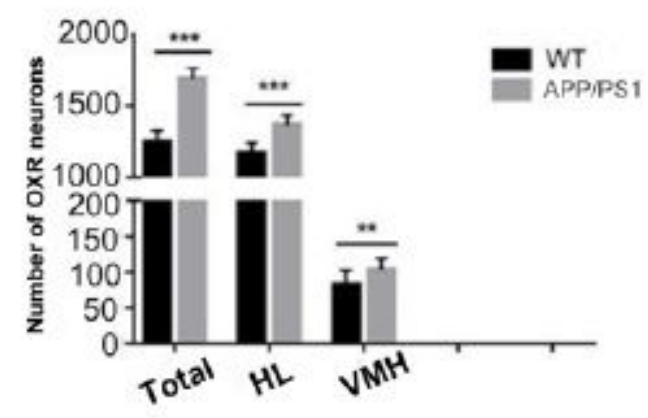

$\mathbf{F}$

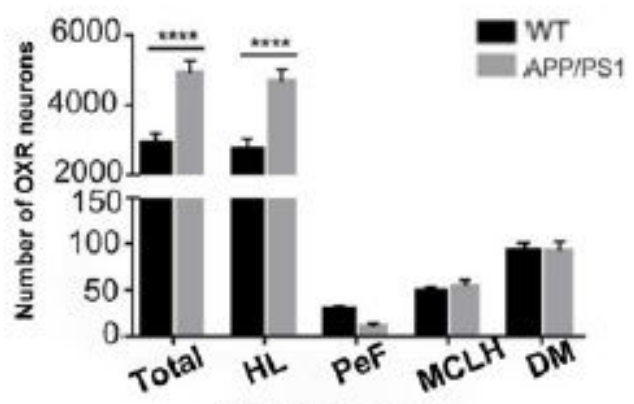

Subreigon areas

Figure 4

Orexin A-immunoreactive neurons in the anterior, central, and posterior sectors of the tuberal hypothalamus in coronal view. $(A, B)$ The slices collected from the anterior sector were used for immunohistochemical staining for orexin $A$ (brown) and quantitative analysis orexin A positive neurons. $(C, D)$ The slices from the central sector were used for immunohistochemical staining for orexin $A$ (brown) and quantitative analysis orexin A positive neurons. $(E, F)$ The slices from the posterior sector 
were used for immunohistochemical staining for orexin A (brown) and quantitative analysis orexin A positive neurons. LH: lateral hypothalamus area; PSTH: parabrain nucleus; PEF: perifornix nucleus; $\mathrm{PH}$ : posterior hypothalamic nucleus; VMH: ventromedial hypothalamic nucleus; MCLH: magnocellular nucleus of the lateral hypothalamus; dorsomedial hypothalamic nucleus. Scale bar: $100 \mu \mathrm{m}$. Data expressed as means $\pm S E M(n=6-8)$. *Pख0.05, $* * P \llbracket 0.01, * \star * P \llbracket 0.001$. Data were analyzed using Student's ttest.
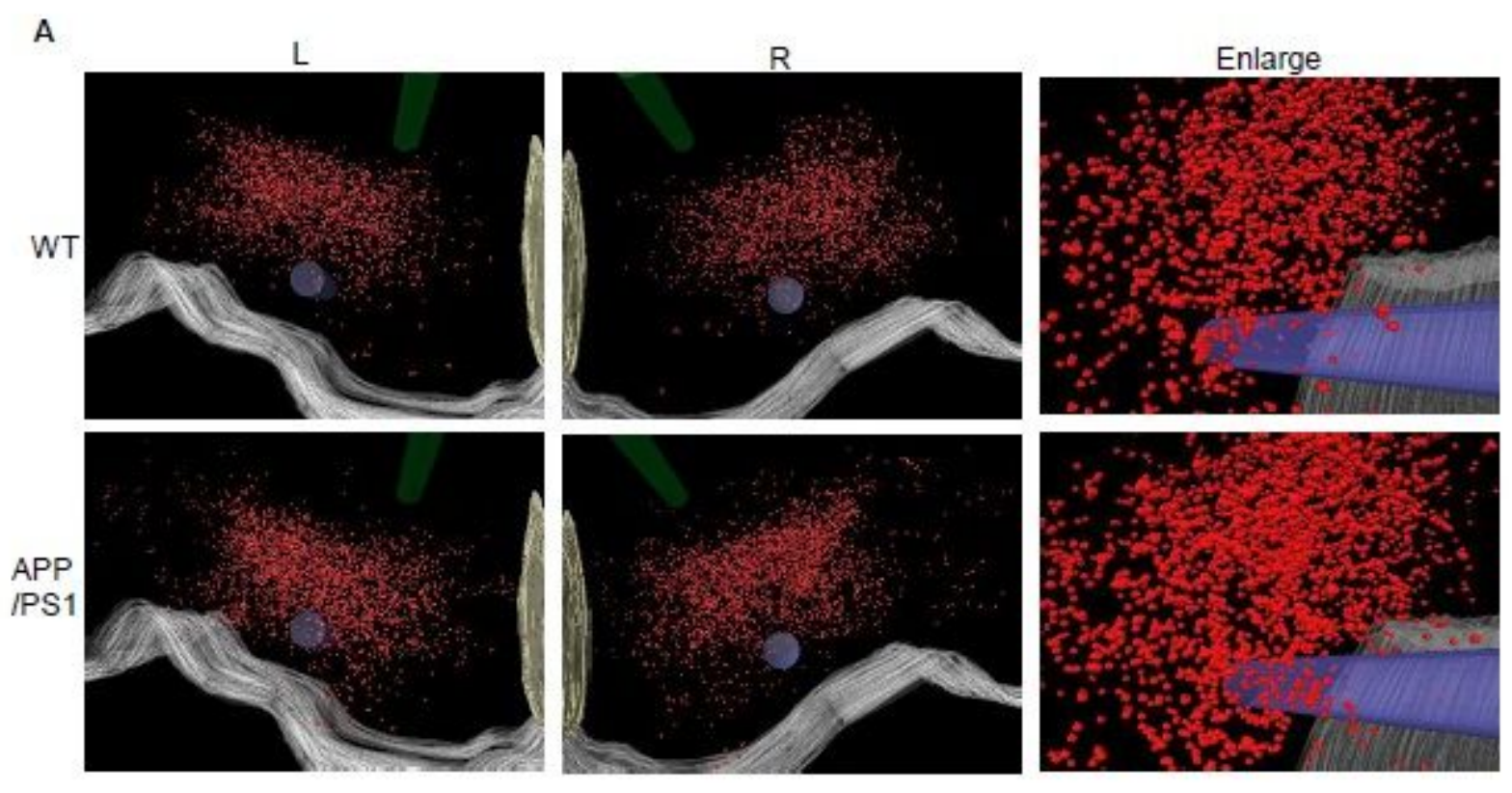

B

L

$\mathrm{R}$

Enlarge
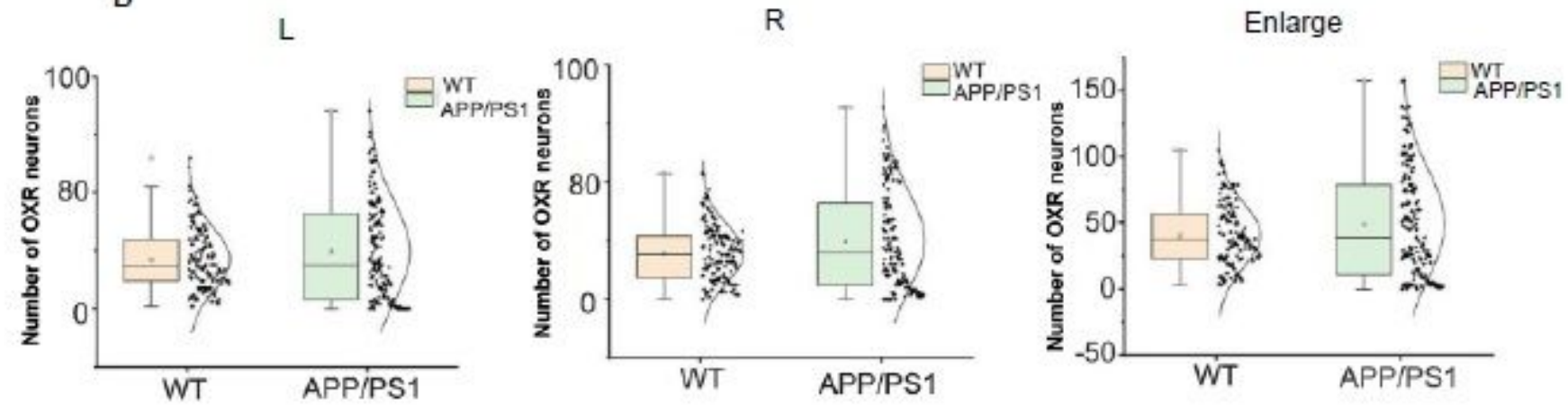

\section{Figure 5}

Distribution of orexin A-immunoreactive neurons in the WT and APP/PS1 mouse. (A) Orexin A neurons on both sides of the WT and AD mice. Each bright red dot represents a single orexin-immunoreactive neuron. Other three-dimensional structures are as follows: Pale yellow-3rd ventricle; Light greenmammillothalamic tract; Violet-fornix; Grey-ventral floor. (B) The Box plot and Normal curve demonstrate the distribution of the total number of ORX-ir neurons in the WT and APP/PS1 mice. The median, lower and upper quartile, an extreme case, the outlier was estimated using the Box plot. 


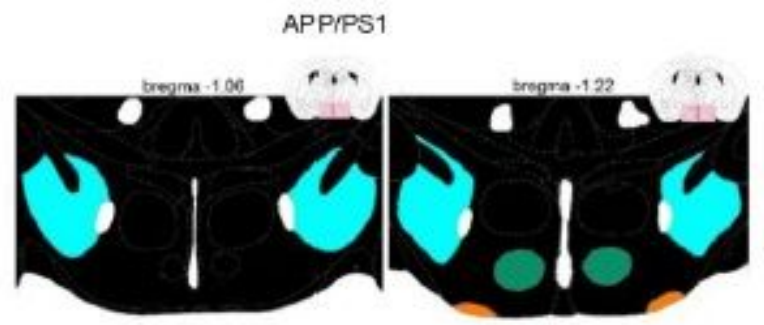

B
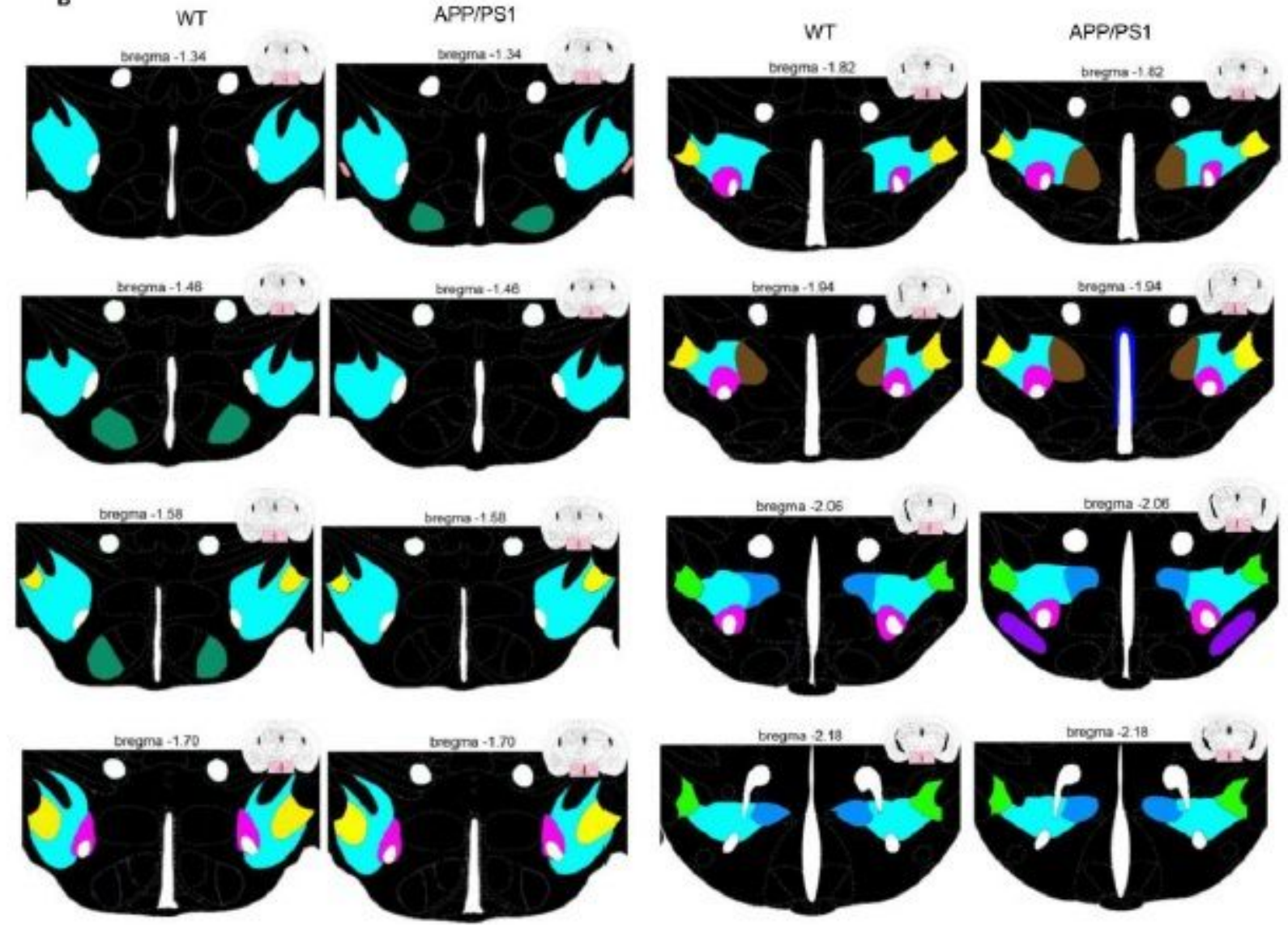

c APPIPS1

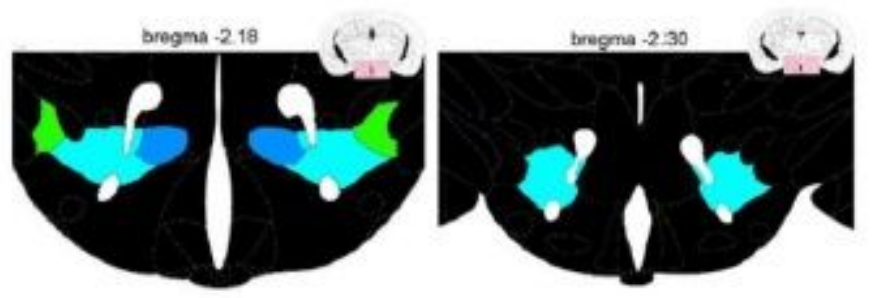

Figure 6

Sections are ordered from rostral to caudal, the hypothalamus was inconspicuously subdivided by the splitting dotted line, schematic drawings showing the general morphology of the nucleus orexin $A$ immunoreactive distributed in the (A) ORX-ir neurons were shown from distence of $-1.06 \mathrm{~mm}$ and $-1.22 \mathrm{~mm}$ away from the bregma (the reference zero point) in APP/PS1 mice. (B) ORX-ir neurons were shown from distence of $-1.34 \mathrm{~mm}$ to $-2.18 \mathrm{~mm}$ away from the bregma. (C) (A) ORX-ir neurons were shown from distence of $-2.18 \mathrm{~mm}$ and $-2.30 \mathrm{~mm}$ away from the bregma in APP/PS1 mice (6 mice/group). 
A

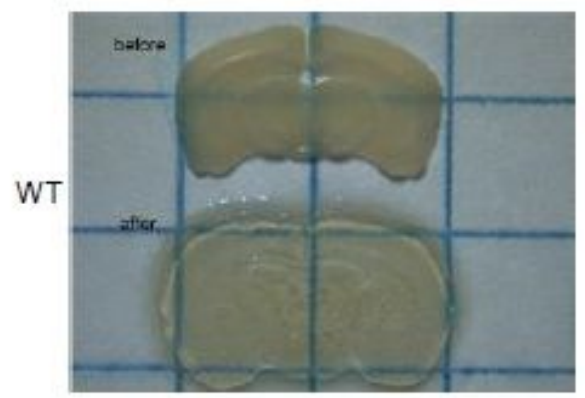

C
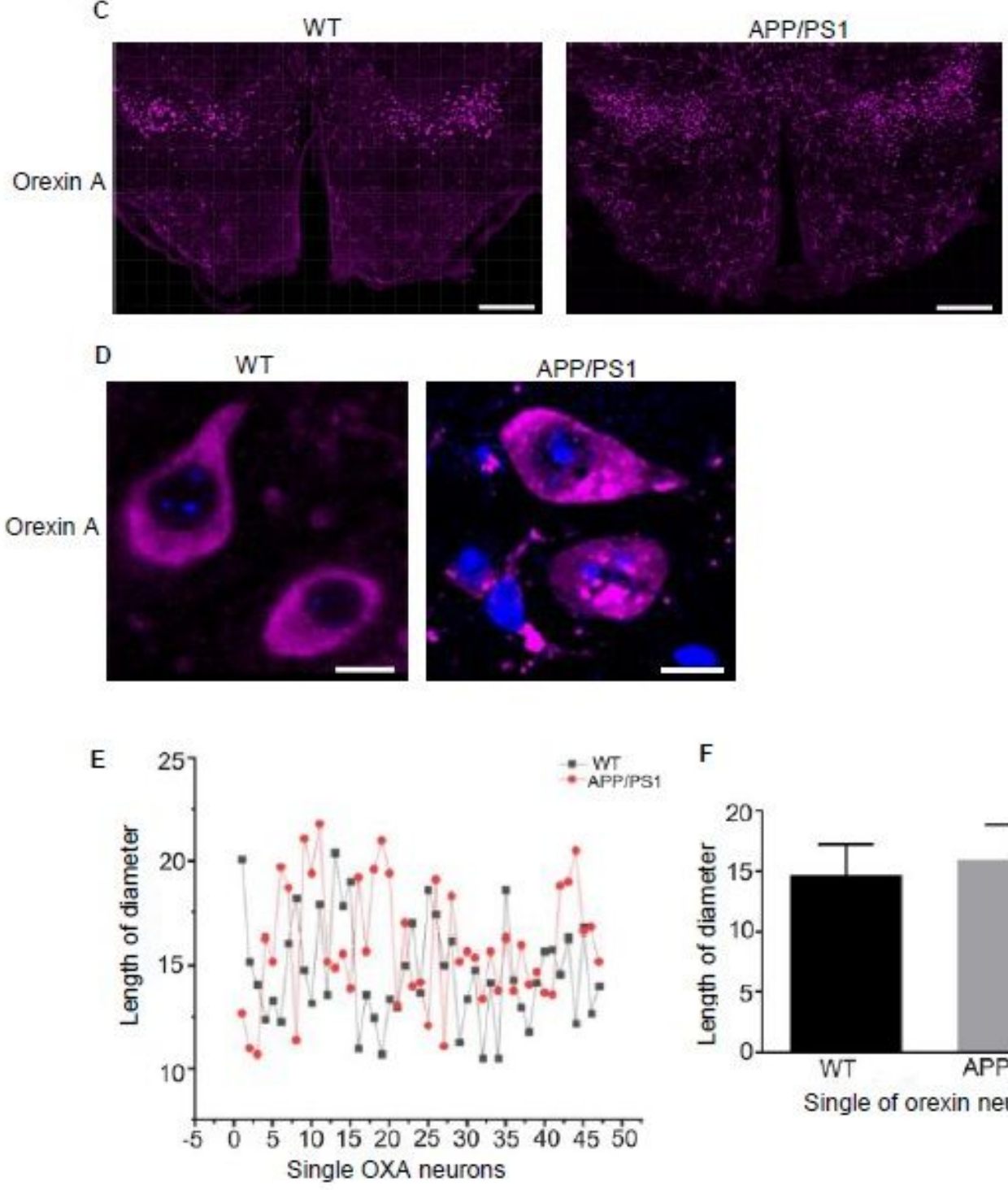

F

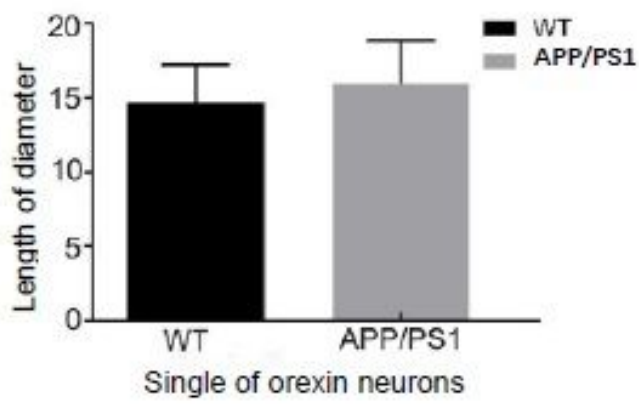

Figure 7

RapiClear cleared mouse brain. (A) The change of mouse brain after optical clearing. (B) Immunofluorescent staining against OXA-ir (red) and anti- $\beta$-Amyloid (green) antibody in the whole RapiClear cleared brain. (C, D) Immunofluorescent staining and magnification for orexin A neurons (purple), DAPI staining was to show the nuclear (blue). Scale bars: $100 \mu \mathrm{m}(\mathrm{E})$ Linear graph show the 
diameter of a single cell of WT and APP/PS1 mice (Y-axis units: micrometer). (F) quantitative analysis of the diameter for orexin A neurons.

\section{Supplementary Files}

This is a list of supplementary files associated with this preprint. Click to download.

- supplementarytable.docx 